\title{
Entre Pais e Filhos: Encontros com a Cultura dos Videogames
}

Entre Padres e Hijos: Encuentros con la Cultura de los Videojuegos

Between Children and Parents: Videogame Culture Histories

\author{
Renata Fischer da Silveira Kroeff \\ Universidade Federal do Rio Grande do Sul, Rio Grande do Sul/Brasil \\ Póti Quartiero Gavillon \\ Universidade Federal do Rio Grande do Sul, Rio Grande do Sul/Brasil
}

Lígia Carangache Kijner

Universidade do Vale do Rio dos Sinos, Rio Grande do Sul/Brasil

Cleci Maraschin

Universidade Federal do Rio Grande do Sul, Rio Grande do Sul/Brasil

\begin{abstract}
Declaração de Direito Autoral
A submissão de originais para este periódico implica na transferência, pelos autores, dos direitos de publicação impressa e digital. Os direitos autorais para os artigos publicados são do autor, com direitos do periódico sobre a primeira publicação. Os autores somente poderão utilizar os mesmos resultados em outras publicações indicando claramente este periódico como o meio da publicação original. Em virtude de sermos um periódico de acesso aberto, permite-se o uso gratuito dos artigos em aplicações educacionais e científicas desde que citada a fonte conforme a licença CC-BY da Creative Commons.
\end{abstract}

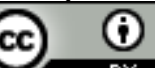

Creative Commons Atribuiç̃o 4.0 Internacional.

\section{Resumo}

Os videogames têm se constituído como um objeto de estudo para diversas áreas de conhecimento, criando um campo de pesquisa heterogêneo e com controvérsias relacionadas a aspectos positivos e negativos sobre as experiências de jogo. Com sua popularização no Brasil a partir da década de 1970, atualmente existe uma geração de adultos que cresceu jogando jogos digitais. O presente estudo visa abordar o que acontece quanto essa geração de jogadores constitui família e segue jogando videogames, agora com seus filhos. A estratégia metodológica escolhida consistiu na realização de entrevistas com pais e mães que jogam videogame com seus filhos. A pesquisa teve a participação de oito pais e duas mães. A estratégia metodológica escolhida, assim como a análise dos registros das entrevistas seguiu a abordagem sistêmica dos estudos da família e dos estudos da cognição enativa. Tal aporte teórico embasa nossa compreensão dos resultados da pesquisa. Em relação a decisões quanto ao acesso dos filhos aos jogos, o conhecimento empírico sobre a experiência de jogar videogame pareceu ser mais considerado do que o conhecimento conceitual-declarativo ao qual os participantes têm acesso na cultura. Observou-se que práticas envolvendo os videogames podem envolver formas interessantes de socialização em família e em outros contextos sociais.

Palavras-chaves: Família; Videogame; Aprendizagem; Comunicação.

\section{Resumen}

Los videojuegos se han constituido en un objeto de estudio para diversas áreas de conocimiento, creando un campo de investigación heterogéneo y con controversias relacionadas a aspectos positivos y negativos sobre las experiencias de juego. Con su popularización en Brasil desde los años 1970, hoy 
existe una generación de adultos que creció jugando videojuegos. El presente estudio aporta lo que sucede cuando esta generación de jugadores constituye familia y sigue jugando videojuegos, ahora con sus hijos. La estrategia metodológica elegida consistió en la realización de entrevistas con padres y madres que juegan videojuego con sus hijos. La investigación tuvo la participación de ocho padres y dos madres. La estrategia metodológica elegida, así como el análisis de los registros de las entrevistas siguió el abordaje sistémico de los estudios de la familia y de los estudios de la cognición enativa. Tal aporte teórico es la base de nuestra comprensión de los resultados de la investigación. Las decisiones al respecto del acceso de los hijos a los juegos y el conocimiento empírico de la experiencia de jugar videojuego és más valorado que el conocimiento conceptual-declarativo al que los participantes tienen acceso en la cultura. Además, se observó que las prácticas con los videojuegos pueden ser formas interesantes de socialización en familia y en otros contextos sociales.

Palabras claves: Familia; Videojuego; Aprendizaje; Comunicación.

\begin{abstract}
Video games have been consolidated as an object of study for several areas of knowledge, creating a heterogeneous research field with negative and positive controversy surrounding the experiences of playing. With its widespread popularity in Brazil starting with the 70's, there is no a generation of adults that grew up playing such digital games. This study aims at approaching the subject of what happens when this generation of players start a family and carry on playing their video-games, now with their children. The methodological strategy chosen is that of interviews with parents that play with their children. The research has had the participation of eight fathers and two mothers. The methodological strategy chosen, as well as the analysis of interview records, followed the systemic approach of family studies and studies of enactive cognition. Such theories base our understanding of the research results. In what regards their decisions as to their children's access to games, empiric knowledge about the experience of playing video game seemed to be more regarded then the declarative-conceptual knowledge that the participants usually get from their cultural backgrounds. It has been observed that practises involving video games can involve interesting ways of family socialization in other social contexts.
\end{abstract}

Keywords: Family; Video games; Learning; Communication.

\section{Introdução}

Os videogames foram criados há cerca de 50 anos nos EUA e se popularizaram rapidamente, assumindo uma importante presença em muitas culturas. Em razão disso, nas últimas décadas, videogames têm se constituído em objeto de estudo para diversas áreas de conhecimento, criando um campo de pesquisa heterogêneo e controverso, principalmente relacionado a aspectos benéficos ou maléficos em relação ao desenvolvimento, aprendizagem e relacionamentos.

No campo da educação, estudos têm apontado para a dimensão educativa dos videogames, defendendo que esses podem contribuir para a aprendizagem de conteúdos curriculares (Leffa, Bohn, Damasceno, \& Marzari, 2012; Alves, 2008; Cani, Pinheiro, Santiago, \& Soares, 2017; Amorim, Oliveira, Santos, \& Quadros, 2016; Castro Castro, Muñoz González, \& Brazo Millán, 2018; Faella \& Luca, 2015); assim como para a discussão de novas estratégias didáticas no contexto escolar (Gee, 2009; Gómez-Álvarez, Echeverri, \& González-Palacio, 2017; Ortiz-Colón, Jordán, \& Agredal, 2018; Castro \& Gonçalves, 2018). Além disso, há estudos apontando os videogames como ferramentas interessantes para a promoção saúde (Dias, Domingues, Tibes, Zem-Mascarenhas \& Fonseca, 2018; Baum \& Maraschin, 2016 e 2017; Meneghini, 
Barbosa, Mello, Bonetti, \& Guimarães, 2016; Ramos \& Segundo, 2018; Vojciechowski et al., 2017; Ramos, Fronza \& Cardoso, 2018; Martel, Colussi \& Marchi, 2016; Natal et al., 2016). Por outro lado, estudos evidenciam que o uso recorrente de videogames pode favorecer a) relações de adição e dependência (Abreu, Karam, Góes \& Spritzer, 2008; Suzuki, Matias, Silva \& Oliveira, 2009; Salas-Blas, MerinoSoto, Chóliz \& Marco, 2017; Marco \& Chóliz, 2017), b) comportamentos agressivos ou violentos (Alves, 2002, 2004), c) isolamento social (Kenski, 1995; Paiva \& Silva Costa, 2015) e d) condutas sedentárias (Dumith et at., 2010; Frutuoso, Bismarck-Nasr \& Gambardella, 2011; Sousa \& Silva, 2017; Ferrari, Araújo, Oliveira, Matsudo \& Fisberg, 2015; Lucena, Cheng, Cavalcante, Silva \& Farias Júnior, 2015; Ferreira, Rombaldi, Ricardo, Hallal \& Azevedo, 2016).

Apesar de tais controvérsias, a indústria dos games alcança recordes de vendas, sendo responsável pela criação de jogos que ultrapassam os anteriores, mesmo no dia do seu lançamento - como foi o caso do jogo Grand Theft Auto V (Wingfield, 2013). Os jogadores são crianças e adultos, homens e mulheres, pertencentes a diversas culturas e contextos sociais (Cruz Junior \& Cruz, 2016). Os jogos têm histórias bem elaboradas, gráficos cada vez mais realistas e design que possibilitam adotar uma grande variedade de performances e estratégias. Algumas dessas narrativas de jogo são longas e exigem horas de dedicação e envolvimento para se ter efetividade no jogo.

Quando foram desenvolvidos, os
primeiros jogos de videogames eram disponibilizados em máquinas de fliperama, denominadas arcades. Por algum tempo foram objeto de divertimento para um público infanto-juvenil masculino (Newman, 2013). Contudo, nas últimas décadas, os jogos digitais para consoles, computadores e, mais recentemente, para smartphones se popularizaram e se consolidaram em muitos países como um dos principais artefatos de entretenimento para diversos usuários, sem restrição de idade ou de gênero. Os jogadores que iniciaram sua experiência com os videogames na época de seu surgimento e que se mantêm jogando são agora adultos e, muitos deles, constituíram famílias (Newman, 2013). Os videogames, que anteriormente eram acessados nos espaços coletivos, hoje são eminentemente jogados no domínio privado. Cabe então indagar como jogadores, hoje pais, se relacionam com os videogames e com seus filhos.

Consideramos família um domínio de manutenção de laços de parentalidade que pode se configurar a partir de interações de apoio mútuo no conviver, em proximidade física ou emocional. Se estrutura por meio do compromisso entre seus membros, tanto quanto porque crescem aí imersos no percurso de seu viver (Maturana, 1998). A compreensão das relações entre os integrantes de uma família pode ser abordada a partir da visão de seus membros, mas também a partir dos padrões de comportamentos constituídos por eles, no acontecer de seu viver. Os sujeitos, seus modos de existência, estão sempre em conexão com os domínios nos quais se constituem. Tal domínio não é somente um ambiente externo que os influenciam, e sim um sistema no qual sujeito e domínio se transformam em congruência. Sujeito e domínio agem em correspondência um com o outro promovendo ações circulares e processuais recorrentes que os fazem variar, modificando sua estrutura no transcurso histórico de seu mútuo acoplamento. Desse modo, podemos estender a dinâmica familiar cotidiana para além das relações interpessoais, incluindo as relações com os objetos, em nosso caso, com o objeto técnico, o videogame. Mas essa extensão, ao considerar a emergência em um sistema de fenômenos globais ou de manutenção de padrões, ultrapassa também a pessoalidade, ao considerar efeitos de conjunto.

Jogar videogame tem se constituído como uma atividade comum para crianças, jovens e adultos. Algo para fazerem juntos, potencializando momentos de convivência em família, ao mesmo tempo em que a diversidade de controvérsias envolvendo os jogos digitais pode ser fonte de dúvidas, inseguranças e configurar desafios para os pais em relação à educação dos filhos. Dessa forma, indagamos 
como os videogames participam das relações intergeracionais, propondo investigar a experiência de pais e mães que jogam videogame junto com seus filhos e/ou filhas. Interessa-nos estudar como esses pais compreendem os videogames, em suas potencialidades como atividade familiar de convivência e ludicidade, assim como se estabelecem as relações entre as dinâmicas familiares e a cultura dos jogos digitais. Para isso, conversamos com pais e mães que jogam videogames com seus filhos.

A seguir, apresentaremos um breve histórico do desenvolvimento da cultura dos videogames. Após, apontamos a estratégia metodológica escolhida, assim como a análise dos registros das entrevistas. Mas antes vamos trazer alguns conceitos da abordagem enativa que decorre do trabalho de Francisco Varela, iniciado na teoria da autopoiese (Humberto Maturana \& Francisco Varela, 2004). Tal aporte teórico embasa nossa discussão dos resultados da pesquisa.

A abordagem enativa (Varela, Thompson, \& Rosch, 2001) trata a cognição de modo corporificado. Em contraponto a uma abordagem mentalista, a cognição é concebida como uma ação corporal, processual e configurada pela estrutura atual que emerge de padrões sensório-motores recorrentes de ação e percepção. Os padrões sensório-motores se modulam a partir do acoplamento com diferentes circunstâncias da experiência cotidiana, que incluem humanos e nãohumanos. Essa abordagem é importante, pois uma das críticas comumente feitas aos videogames é que estimulam a atividade sensório-motora em detrimento da reflexão, considerando-os como opostos. Ora, é justamente essa oposição entre corpo e pensamento que a abordagem enativa vem questionar, produzindo uma articulação entre ambos.

Varela (1992), distingue dois tipos de conhecimento, o saber-fazer e o saber-o-que. $\mathrm{O}$ primeiro, envolve a imediatidade de ações e, o segundo, conhecimentos deliberados, decorrentes da construção de juízos sobre as ações. A enação articula conhecimentos advindos do confronto imediato/pré-reflexivo com o conhecimento reflexivo, dando ênfase ao primeiro, uma vez aquele tem sido considerado como um modo de conhecer inicial, superado pela reflexão.

Com isso, o mundo de um sujeito cognitivo não é um domínio exterior e predeterminado que deve ser adequadamente representado no cérebro, mas um domínio relacional, que precisa ser atuado, constantemente trazido à existência, através da ação do sujeito cognitivo em seu modo de acoplamento com o mundo. (Baum \& Maraschin, 2018).

A compreensão desse domínio relacional entre pais e filhos será realizada a partir de três modos articulados da atividade corporal: a) a autoregulação; b) o acoplamento sensório-motor e c) a interação intersubjetiva (Thompson \& Varela, 2001). A autoregulação é um processo necessário à manutenção da vida e à sensibilidade ao mundo, estar aberto à experiência. Pode ser entendida como uma oscilação entre uma atenção difusa e focada. $\mathrm{O}$ acoplamento sensório-motor emerge pela recorrência de ações, emoções e percepções que adquirem uma estabilidade temporária, por isso pode ser definido como metaestável. Diante de uma perturbação que evidencie a não eficácia de determinada atividade sensóriomotora, outros padrões podem ser constituídos. As interações intersubjetivas são compreendidas como a articulação entre a cognição e as experiências afetivas de si e de outra pessoa.

A experiência de tornar-se jogador emerge em um emaranhado desses três processos recorrentes em cuja centralidade está o corpo que se modifica estruturalmente pelos acoplamentos. A experiência subjetiva cotidiana pode ser compreendida como um processo de enatuação de um self no processo atencional, esse self pode emergir ou se dispersar de acordo com o exercício da atenção (Baum \& Maraschin, 2018). 
Outro conceito interessante a considerar na interação entre pais e filhos é a ideia de um espaço de afinidade que se articula ao que comentamos como interação intersubjetiva. $\mathrm{O}$ conceito cunhado por Gee $(2003,2007)$ não considera somente o jogo, mas as redes sociais de interação derivadas do mesmo. $\mathrm{O}$ autor prefere denominar de espaços de afinidade ao invés de comunidades pois essa última pode levar a sentidos de pertencimento e de relações de consensualidade que não se adequam ao conjunto das relações existentes nos espaços de trocas gerados pelos videogames.

Ao analisar os fóruns do game "Age of Mythology", Gee (2004) evidencia que os mesmos são formados pelo compartilhamento de ações e conteúdos mais do que por marcas identitárias ou vínculos institucionais. Gee descreve algumas características dos fóruns que possibilitam ser pensados como espaços de afinidade: (a) a participação é aberta a qualquer usuário; (b) iniciantes e veteranos compartilham o mesmo espaço; (c) os participantes têm poder de definir e transformar o ambiente; (d) conhecimento é compartilhado entre os jogadores; (e) existem muitas formas de participar e (f) a participação nos espaços de afinidade remodela o próprio o jogo mesmo, ao propiciar feedbacks aos desenvolvedores de jogos ou por explicitar modos de modificar os jogos que assim o permitem ("modding").

Os espaços de afinidade se relacionam a algum conteúdo. É um espaço de algo/ espaço para algo. Para o autor acima citado, é possível analisar o conteúdo nesses espaços de afinidade de dois modos. De um modo direto, ou seja, de como ele está organizado, o que está presente e o que está ausente. Mas também podemos pensar de um modo indireto, tal como nos modos como os integrantes interagem com ele. No caso dos videogames, focar o conteúdo, de um modo direto, é perguntar-se sobre o design desses jogos, enquanto que focar na via interacional é perguntar como as pessoas organizam seus pensamentos, crenças, valores ações e as interações sociais em relação aos sinais que estão disponíveis nos jogos (Gee, 2004). Mas, o mais interessante nos videogames é que podemos interagir diretamente com os conteúdos no tempo real das estratégias do jogo. Conteúdo e interação estão juntos uma vez que o avatar é, ao mesmo tempo, parte e não parte do conteúdo do jogo, pois também depende de um jogador que o opere. Essa imersão como conteúdo do jogo é uma experiência inusitada que pode ampliar modos de experiência de si.

\section{Os videogames e a cultura dos jogos digitais}

Os primeiros jogos de videogames surgiram no início da década de 1960. O americano William Higinbotham criou o jogo para computador Tennis for Two, que consistia em uma imagem gráfica simples de apenas duas barras, representando raquetes, e um ponto luminoso que se deslocava na tela representando uma bola. Pouco tempo depois, no Massachusetts Institute of Technology (MIT), um grupo de estudantes liderados por Steve Russel criou o jogo de batalha espacial Spacewar para testar novas capacidades do computador com o qual estavam trabalhando na época. Posteriormente, Spacewar foi o primeiro jogo a ser lançado em versão arcade $^{1}$, mas tinha regras de jogabilidade bastante complexas, o que exigia dos jogadores um estudo muito aprofundado de seu manual. Em vista disso, o primeiro jogo arcade a ser comercializado e fazer sucesso foi o Pong, lançado pela empresa Atari no início dos anos 70. Um jogo bem mais simples, inspirado na ideia de um jogo de tênis de mesa. Um dia após a instalação da máquina do Pong em um bar, ele tinha ficado tão popular que diversas pessoas faziam fila para jogar antes mesmo do bar abrir (Gularte, 2010). A partir disso, muitos outros jogos arcades surgiram. Foram criados os primeiros jogos de corrida (Gran Trak 10, em 1974), jogos de perseguição em labirinto (Gotcha, em 1973), jogos com cabines e o primeiro jogo em

1 Máquinas de fliperama. Eram distribuídas em lojas, bares e centros de entretenimento (Gularte, 2010). 
primeira pessoa de corrida (Night Driver, em 1976).

Em 1977, pouco tempo depois dos primeiros videocassetes chegarem ao mercado (1971), foi lançado o primeiro console ${ }^{2}$ de videogame doméstico para jogar em casa, o Telejogo, que possuía apenas um jogo em sua programação. Posteriormente, no mesmo ano foram lançados diversos novos aparelhos que permitiam trocar de jogo, dentre eles o famoso VCS 2600 da Atari, determinando o modelo de como a indústria se configuraria: cada aparelho de cada empresa possuiria uma biblioteca de jogos, muitas vezes exclusiva, compatível com um único console.

Durante os anos 1980, os arcades continuavam em expansão, muitos dos jogos eram primeiro desenvolvidos para arcade (pela facilidade técnica) e mais tarde eram adaptados para os diferentes consoles domésticos. Space Invaders (1978), Pac-Man (1980) e Mário (1981) seguiram este padrão, até o lançamento do Famicom (Nintendo Family Computer) em 1983, que pela primeira vez trazia jogos exclusivos que não estavam anteriormente disponíveis nos arcades. Super Mario Bros (1985) foi o mais importante. Também em 1985, uma empresa rival, a Sega, lançou o Master System, marcando os anos 1980 com a década dos 8-bits ${ }^{3}$. E no final de 1988, tornou a corrida pelo desenvolvimento de consoles mais acentuada com o lançamento do Mega Drive, dando um fim à era dos 8-bits e iniciando da década dos 16-bits.

No início da década de 1990, os videogames domésticos já haviam evoluído muito em comparação aos arcades, fazendo-se presente na casa de milhares de pessoas em vários países. Consoles portáteis como o Game Boy (1989) e o Game Gear (1990) já haviam sido lançados, e a rivalidade entre as grandes

\footnotetext{
${ }^{2}$ Aparelho onde se introduz fitas ou CDs de jogos para poderem ser jogados.

${ }^{3}$ A capacidade de memória dos consoles da época, que determinava suas capacidades básicas, e era usada para determinar os avanços entre uma geração a outra, entrando em desuso atualmente por outros atributos.
}

marcas era grande quando ocorreu o lançamento do console de 16-bits da Nintendo, o Super Nintendo (1990). Paralelamente aos consoles domésticos e portáteis, geralmente comercializados para o público infantil, os jogos digitais de computador continuavam a se desenvolver. Possuir e operar um computador não era tarefa fácil e isso restringia o acesso a esses jogos, mas não impediu que deixassem seu legado. O primeiro jogo de tiro em primeira pessoa (ou first-person shooter, FPS) foi o jogo para computador Wolfeinstein 3D, lançado em 1992, que se tornou o gênero mais popular de jogos até os dias atuais.

O final dos anos 1990 é um testemunho da popularidade dos jogos com o lançamento de Pokemón, o primeiro grande sucesso televisivo baseado em uma franquia de videogames, e o fenômeno dos animais de estimação virtuais Tamagotchi, que se espalharam pelas escolas do mundo todo. Outro legado importante foi que, a partir do fim da década de 1990, os jogos deixaram de ser um brinquedo vendido para crianças. O console Playstation marcou a entrada da empresa Sony na indústria dos jogos com uma campanha publicitária destinada aos públicos jovem e adulto.

Os consoles e jogos de computador se tornaram mais compatíveis com o avanço da tecnologia, permitindo que alguns títulos fossem desenvolvidos de maneira universal e pudessem ser lançados para todos os aparelhos de videogame e computadores ao mesmo tempo. Isso permitiu que diversas grandes franquias se estabelecessem, como Final Fantasy, Assassin's Creed, Mortal Kombat, Street Fighter. Muitas delas adaptadas para o cinema e televisão.

Nos anos 2000, os consoles Nintendo Wii (2006) e Nintendo DS (2004) trouxeram jogos para um público ainda mais abrangente. 
Com um dispositivo que se assemelha a um controle remoto de TV, o Nintendo Wii foi amplamente divulgado e vendido para pessoas que não estavam familiarizadas com os controles com muitos botões dos consoles tradicionais, como o público feminino e idosos. Os novos controles de movimento desses consoles permitem que os jogadores usem o próprio corpo para jogar, algo muito mais compatível com os movimentos corporais, o que incrementou o uso de jogadores não habituais. O Nintendo DS foi amplamente vendido com jogos que prometiam exercitar o raciocínio e a memória. A Nintendo também apresentou uma linha especial para quem apresentasse problemas de visão, o Nintendo DS XL (2009), com uma tela 93\% maior que o modelo tradicional.

A popularização da internet trouxe ainda uma nova dimensão para os jogos online, com a criação dos chamados MMOs (massive-multiplayer on-line), que permitem que centenas de jogadores se conectem ao mesmo tempo em uma única sessão de jogo. Os custos para se operar um servidor para manter esses jogos estabeleceu um novo vínculo entre jogadores e desenvolvedores. Estes passaram a cobrar mensalidades pelo acesso ao jogo, em vez da tradicional venda da versão completa. Dessa forma, ocorreu uma modulação na concepção comercial dos jogos, que passaram a ser considerados também como possibilidade de oferta de um serviço, e não apenas como um produto fechado. Esse foi o precursor do atual modelo de jogos gratuitos com microtransações ${ }^{4}$, permitindo o acesso gratuito a jogos que, aliado à disseminação de aparelhos portáteis com conexão à internet, como tablets e celulares, é responsável por dar disponibilizar milhares de jogos a qualquer pessoa.

\section{Método}

O presente estudo se configura como uma pesquisa qualitativa de caráter exploratório. Se insere em um projeto mais abrangente denominado "Oficinando em Rede: videogames e espaços de afinidade" em desenvolvimento pelo Núcleo de Ecologias e Políticas Cognitivas (NUCOGS) da Universidade Federal do Rio Grande do Sul (UFRGS), aprovado pelo Comitê de Ética em Pesquisa do Instituto de Psicologia da universidade.

A estratégia metodológica escolhida para este estudo consistiu na realização de encontros presenciais e virtuais com pais e mães que jogavam videogame com seus filhos e/ou filhas. Os encontros presenciais foram gravados em áudio e posteriormente transcritos. Os encontros virtuais ocorreram por meio de um software para troca de mensagens instantâneas com conexão à internet. Todos os participantes assinaram um termo de consentimento livre e esclarecido.

A pesquisa teve a participação de oito pais, com idades entre 26 e 42 anos, e duas mães, com idade entre 29 e 35 anos. A idade atual dos(as) filhos(as) variou entre 4 e 14 anos.

Para a realização e a análise das entrevistas, partimos da posição de que conversar sobre um acontecimento, buscando explicitá-lo, não consiste na representação de uma realidade objetiva, mas que a própria ação de conversar constitui a emergência de uma experiência que atualiza a anterior (Maturana, 2001). Tal situação consiste na proposição de uma reformulação de uma experiência em um dado domínio explicativo. Dessa forma, para a análise dos registros das entrevistas, propusemos discutir situações relacionadas a jogar videogame com os filhos, vivenciadas pelos pais e pelas mães participantes da pesquisa, a partir de suas reformulações dessas experiências relacionadas a três aspectos principais: a inserção na cultura dos videogames, a composição de redes sociais envolvendo as práticas com os jogos digitais e a construção de relações entre aprendizagem e entretenimento.

\footnotetext{
${ }^{4}$ Venda de partes pequenas dos conteúdos do jogo em parcelas, de acordo com o interesse do jogador.
} 


\section{Resultados e discussão Start game: o videogame no convívio familiar}

A fim de compreender $\mathrm{o}$ domínio relacional entre pais e filhos com os videogames, pedimos que os participantes da pesquisa produzissem narrativas sobre suas Tabela 1

Idade que iniciam a jogar videogame

\begin{tabular}{|c|c|c|c|c|c|}
\hline Nome $^{5}$ (Gênero) & Idade & Começou a jogar & Filhos/as (Gênero) & Idade & Começou a jogar \\
\hline Link (M) & $37 \mathrm{a}$ & $10 \mathrm{a} \mathrm{c} /$ amigos & Zelda $(\mathrm{F})$ & $13 \mathrm{a}$ & $12 \mathrm{a} \mathrm{c/} \mathrm{o} \mathrm{pai}$ \\
\hline Alex Kidd (M) & $33 a$ & $7 \mathrm{a} \mathrm{c/} \mathrm{amigos}$ & Egle (M) & $10 \mathrm{a}$ & $4 \mathrm{a} \mathrm{c/} \mathrm{amigos}$ \\
\hline Sonic (M) & $39 a$ & $8 \mathrm{a} \mathrm{c} / \mathrm{amigos}$ & Tails (M) & $14 \mathrm{a}$ & 3a c/o pai \\
\hline Mário (M) & $26 \mathrm{a}$ & $5 \mathrm{a} \mathrm{c/} \mathrm{o} \mathrm{pai}$ & Luigi (M) & $7 \mathrm{a}$ & 3a c/ o pai \\
\hline Chun-Li $(\mathrm{F})$ & $29 a$ & $5 \mathrm{a} \mathrm{c/primos}$ & $\operatorname{Ken}(\mathrm{M})$ & $6 a$ & $5 \mathrm{a} \mathrm{c} /$ primos \\
\hline Blanka (M) & $32 \mathrm{a}$ & $14 \mathrm{a} \mathrm{c/} \mathrm{amigos}$ & Ryu (M) & $4 a$ & $3 \mathrm{a} \mathrm{c} /$ primos \\
\hline Kitana (F) & $35 \mathrm{a}$ & Não jogava & & & \\
\hline Sub-Zero (M) & $42 \mathrm{a}$ & $11 \mathrm{a} \mathrm{c/} \mathrm{amigos}$ & Scorpion (M) & $6 a$ & $4 \mathrm{a} \mathrm{c} /$ amigos \\
\hline Goku (M) & $33 \mathrm{a}$ & $7 \mathrm{a} \mathrm{c/} \mathrm{amigos}$ & Gohan (M) & $4 a$ & 3a c/ o pai \\
\hline Kratos (M) & $34 \mathrm{a}$ & $7 \mathrm{a} \mathrm{c} / \mathrm{amigos}$ & Ares (M) & $8 \mathrm{a}$ & $3 \mathrm{a} \mathrm{c/} \mathrm{o} \mathrm{pai}$ \\
\hline
\end{tabular}

É possível observar duas mudanças relacionadas ao processo de inserção dos pais e dos filhos na cultura dos videogames, considerando a faixa etária e o contexto social no qual iniciaram a jogar. Todos os pais iniciaram sua experiência com videogame após os 7 anos de idade, geralmente com amigos, enquanto que a maioria dos filhos iniciaram entre os 3 e 4 anos, com seus pais. A maior precocidade dos filhos está relacionada a diferentes aspectos. O primeiro, refere-se ao acesso aos videogames, o que está diretamente vinculado ao próprio desenvolvimento da indústria dos videogames, conforme destacamos. Diante do desenvolvimento tecnológico, é esperado que o cotidiano dos filhos esteja mais povoado com objetos técnicos que aquele dos pais. Outro aspecto relaciona-se a uma modulação da prática inicial de jogo. Como iniciaram a jogar muito mais novos, o padrão relacional inicial implicava uma autoregulação a partir de uma atenção sensível aos movimentos realizados pelo adulto, uma atividade sensório-motora baseada na co-presença, estar ao lado, mas com trocas emocionais intensas (Thompson \& Varela, experiências pessoais e familiares. Jogar videogame constituiu atividade vivenciada por diferentes gerações, apresentando caráter transgeracional em todas as famílias participantes da pesquisa. Contudo, tais experiências estiveram muito mais presentes nas histórias de indivíduos do sexo masculino.
2001; Maturana, 2001). Em razão disso, alguns pais relataram que as primeiras experiências de práticas de jogo conjunta entre eles e os filhos correspondiam a encenações destinadas ao entretenimento lúdico dos filhos enquanto eles efetivamente jogavam.

\section{Eu jogava e dava um controle na mão dele para ele não chorar e ele achava que tava jogando. Nessa época, eu jogava Mário Kart no Nintendo 64, um jogo de carrinho, e ele com 3 ou 4 aninhos do meu lado. Então era uma coisa mais lúdica, eu dizia pra ele: "agora, filho, vamos fazer a curva", $e$ inclinava o corpo para o lado e ele me acompanhava inclinando o corpo dele junto. (Sonic, pai de Tails de 14 anos).}

Embora o filho não estivesse efetivamente jogando, a experiência era vivida a partir dos três processos recorrentes autoregulação, acoplamento sensório-motor e interação intersubjetiva (Thompson e Varela, 2001) - cuja centralidade é o corpo, que vai gradualmente se modificando ao coordenar

\footnotetext{
${ }^{5}$ Nomes fictícios inspirados em personagens de videogames, a fim de preservar a identidade dos participantes.
} 
suas ações com as do pai. O acoplamento de um movimento com outro movimento se dá de modo recursivo, através de um histórico de interações que vão entrando em congruência operacional, como no caso de "fazer a curva".

Outro aspecto importante referente à inserção na cultura dos videogames são as situações e contextos nos quais as experiências com os primeiros jogos digitais ocorrem. $\mathrm{O}$ fato de os filhos começarem a jogar ainda na primeira infância pode influenciar para que tais experiências ocorram no contexto da família nuclear, enquanto a maioria dos pais relataram ter iniciado a jogar com amigos ou parentes da família extensa, geralmente primos. Dessa forma, começar a participar dos momentos de jogo desde muito cedo com os pais proporciona o desenvolvimento de um espaço de afinidade (Gee, 2004) entre pais e filhos em torno da cultura do videogame, mais acentuado do que em gerações familiares anteriores.

Eu não jogava muito com meu pai. Não era comum. Eu jogava muito mais sozinho ou com os amigos. O pai não jogava videogame antes. Comprou o videogame pra mim. Ele achava legal jogos de futebol, corrida,.. jogos de esportes e tals, mas não era muito de jogarmos junto. Muito menos do que eu jogo hoje com o meu filho, por exemplo. É uma coisa que nós dois gostamos de fazer. E aí, então hoje eu jogo muito mais com ele do que sozinho também. (Mário, pai de Luigi de 7 anos).

As diferenças intergeracionais nos modos de jogar videogame, torna possível estabelecer um padrão de práticas de jogo de uma geração para a outra, o que acarreta distintas configurações dos espaços de afinidade, devido às diferentes interações intersubjetivas. Na dinâmica das interações entre Mário e seu pai (avô de Luigi), os jogos de videogame não constituíam a principal atividade entre eles. Segundo relato de Mário, costumavam fazer com mais frequência atividades como jogar futebol, assistir desenho animado e passear de carro aos fins de semana.
Os dois iniciaram a jogar videogames juntos, mas tal atividade se configurou como ação pertencente mais ao domínio de interesses de Mário do que de seu pai. O videogame era um artefato, um brinquedo, de Mário, com o qual ele brincava sozinho, com amigos, e às vezes com o pai (avô de Luigi). Por outro lado, a interação que se estabelece entre Mário e seu filho, Luigi, envolvendo o videogame é diferente. A atividade de jogar videogame na relação paternal é modulada, deixando de ser essencialmente uma ação de divertimento para Mário, para se tornar um interesse compartilhado que constitui uma prática de entretenimento e diversão entre pai e filho. Nesse sentido, a prática de jogar videogame entre Mário e Luigi está mais próxima a experiência de constituição de um espaço de afetividade de inserção na cultura dos videogames, no qual a relação geracional é deixada em segundo plano, sendo enfatizada a atenção no processo de trocas e de construção de habilidades do jogo, ou seja, a produção de um espaço de afinidade (Gee, 2004).

\section{É muito legal jogar com eles, dá um ar} de nostalgia. Compramos um Nintendo Wii $U$, porque achei mais adequado pra idade deles, mas também tem o jogo do Mário, que eu cresci jogando. Acredito que o videogame pode ser uma boa forma de distração, brincadeira em equipe ou sozinho. Jogar junto com as crianças é uma forma de diversão em família, então é muito bom; especialmente os meninos se entusiasmam muito quando a família inteira joga reunida. Assim temos prazer em dividir este momento com eles. (Chun-Li, mãe de Ken de 6 anos e de Ryu de 4 anos).

O vínculo criado com os filhos no domínio das práticas de jogo é visto por alguns pais também como possibilidade de conhecimento mútuo, a partir da comparação entre as performances no jogo. Dois pais relataram que, observando a forma como os filhos jogam, buscam fazer relações entre as escolhas feitas durante as partidas, suas 
características de personalidade e o interesse deles em outras atividades. A autoregulação dos pais a partir do acoplamento estrutural no jogo com seus filhos se dá tanto na atenção às suas performances, mas também os leva a atentar sobre como os modos de jogar dos filhos permite uma compreensão de suas ações em outros domínios (Thompson e Varela, 2001). Aqui nota-se uma articulação entre um saber em ação, pré-reflexivo, que tem efeito nas performances, e um saber reflexivo, um saber que produz uma espécie de julgamento sobre ações para além do jogo de videogame (Varela, 1992).

Ela gosta muito de ler ficção adolescente. Eu acho que ela começou a se interessar mais pelo videogame pela interatividade dos personagens, $o$ que lembra as literaturas infantojuvenis. Isso faz que ela interaja melhor com o personagem do que eu, pois gosta de participar de estórias e fantasias já que lê mais, enquanto sou mais prático. Ela entra no personagem. Eu faço a básico para avançar. Como ela curte a imersão do jogo, assim como a imersão de um personagem na história de um livro, ela procura nos mínimos detalhes as melhores armas pro personagem dela, melhores armaduras... Como consequência o personagem dela é melhor, sempre mais avançado que o meu. (Link, pai de Zelda de 13 anos).

A atenção à diferença entre os modos de interagir com o jogo se produz a partir de um conhecimento reflexivo de Link. Tal distinção atua recursivamente sobre a sensóriomotricidade podendo potencializar a invenção de novas performances de jogo, a partir da ação conjunta e trabalho em equipe. Em alguns jogos multiplayer, os jogadores podem competir entre si para ver quem faz mais pontos ou cada jogador pode se responsabilizar por ações diferentes, sendo estas complementares para que ambos consigam atingir objetivos comuns durante a partida. $\mathrm{O}$ mesmo pode ocorrer em jogos singleplayer, quando um jogador controla os movimentos do avatar e quem está observando contribui para a configuração de estratégias, alertando sobre a chegada de inimigos ou dando outras sugestões de caminhos para avançar no jogo.

A gente tem habilidades diferentes. Eu sou mais cauteloso. Ele ou vai muito afoito ou ele não vai. Quando está jogando, às vezes o Luigi é muito ofensivo. Quer resolver logo a fase. Quando a gente tá jogando junto, um fica dando palpite para o outro. Eu tô indo cauteloso e ele dizendo pra mim ir de uma vez. Outras vezes eu fico dizendo pra ele não ir pra algum lugar, porque tem inimigos lá, etc. (Mário, pai de Luigi de 7 anos).

Em relação à escolha dos jogos, quatro pais e as duas mães referiam limitar de alguma forma os jogos aos quais os filhos têm acesso. Quatro pais relataram que não limitam o acesso dos filhos aos jogos e que apenas procuram acompanhar as experiências de jogo, jogando junto, sem criar regras de escolha relacionadas a temáticas, tipos de jogabilidade, faixas etárias recomendadas ou outras características.

Entre os pais que buscam limitar o acesso, uma das razões principais se refere à crença de que alguns tipos de jogos poderiam influenciar o comportamento dos filhos para atitudes consideradas agressivas ou violentas. Em especial, jogos com classificação indicativa para faixas etárias mais elevadas, muito competitivos, de realidade virtual ou em primeira pessoa que envolvem matar pessoas ou realizar outros tipos de atividades ilícitas com uma composição gráfica muito realista.

Nossa preocupação é a confusão entre real e virtual, principalmente neste período em que cada vez mais as realidades têm ficado muito parecidas. Acredito que o videogame, além de uma forma de extravasar, é uma forma de o cérebro treinar a reação para determinadas situações. Logo, o que os pequenos crescem "treinando", principalmente em 
crianças mais sozinhas $e$ introspectivas, pode gerar pessoas violentas, ou crianças condicionadas a atitudes cruéis. (Blanka, pai de Ken de 6 anos e de Ryu de 4 anos).

Em geral, esses pais têm preferência por jogos com temáticas de esportes, super-heróis ou resolução de puzzles simples, multiplayers e com personagens em estilo cartum. Procuram fazer escolhas independentemente da curiosidade ou vontade dos filhos de jogar outros tipos de jogos, considerando isto parte de sua função como pais. Aqui existe um sabero-que que avalia jogos de acordo com os conteúdos e modos de operar com os mesmos.

Acredito que meu papel como pai é servir como um filtro para as coisas do mundo, acompanhando em cada fase de desenvolvimento o que deve e o que não deve chegar até ele, até que ele possa fazer as suas próprias escolhas de forma sensata buscando o que é melhor pra ele. (Sub-Zero, pai de Scorpion de 6 anos).

Contudo, o acesso aos jogos em redes de relações externas ao âmbito familiar também é motivo de preocupação. Nesse sentido, consideram que o convívio dos filhos com outras crianças, fora do espaço familiar de origem, pode provocar situações adversas, como o acesso a jogos não permitidos por eles, em vista de posicionamentos divergentes de outros pais em relação aos videogames.

Nossa maior preocupação é em relação até quando conseguiremos manter o controle dos jogos, tendo em vista que a maioria dos pais não se preocupam, e eles também se divertem na casa dos amigos. Daqui a algum tempo podem querer trazer os jogos que não consideramos bons para dentro de casa. (Chun-Li, mãe de Ken de 6 anos e de Ryu de 4 anos).

Entre os pais que preferem não limitar o acesso aos jogos, dois argumentos principais são apontados para tal escolha. $\mathrm{O}$ primeiro baseia-se na compreensão de que os filhos possuem capacidade de julgamento. Esse argumento encontra fundamento na segurança dos pais em relação à educação no que se refere a valores morais e éticos prévios ensinados a seus filhos.

Eu não faço restrição a jogos e nem a filmes pois confio no julgamento dela. Eu acho que um filho que tem uma boa educação dos pais não é motivo de preocupação. Pois, se a criança sabe o que é certo e errado, vai saber escolher bem com o que quer interagir, seja videogame, filmes, histórias em quadrinhos, situações, culturas ou o que for. Culpar a mídia $e$ o mundo pelas escolhas ruins do filho é tirar dos ombros a responsabilidade de educador. (Link, pai de Zelda de 13 anos).

$\mathrm{O}$ segundo argumento se refere à popularidade dos videogames e à abrangência do acesso aos jogos em contextos de democratização da informação, principalmente na internet. Esses pais relatam a impossibilidade de, efetivamente, conseguirem controlar a que os filhos têm acesso, sentindose impotentes em relação a isso. "Na minha imaginação alguns jogos são menos adequados, principalmente os que têm violência explícita, mas na prática aqueles que eu não compro pra ele, ele olha os vídeos no YouTube" (Alex Kidd, pai de Egle de 10 anos).

Nesse sentido, alguns pais relatam ter vivenciado a situação inversa em suas famílias de origem. Embora seus pais tentassem limitar o acesso, isso não evitava que eles jogassem baixando versões piratas pela internet ou na casa de amigos ou colegas de escola.

Eu deixo ele jogar o que ele quer. Eu acho que, se eu ficar limitando o que ele pode jogar, ele vai jogar igual. Até aumenta a curiosidade mais ainda. Então é melhor ele jogar comigo, de forma que eu possa controlar, do que ele jogar sem eu controlar o que ele tá 
jogando, porque ele vai ter acesso de qualquer jeito. Acho que seria eu querer me enganar, que ele não iria jogar. Porque sei lá, sempre tem um coleguinha que joga. Minha mãe pensa que eu não deveria deixar ele jogar vários jogos que ele joga. Quando eu era criança eu jogava e ela nem sabia. (Mário, pai de Luigi de 7 anos).

Se por um lado existe a quebra de um legado familiar, visto que esses últimos pais não continuam exercendo a função de buscar limitar o acesso dos filhos a alguns tipos de videogames, por outro a tentativa de controle da experiência é modulada, passando a ocorrer no âmbito da criação de significados e dos efeitos que possam vir a emergir. Esses pais dizem participar junto com os filhos da experiência de jogar videogames considerados violentos ou que tenham uma orientação de faixa etária inapropriada para a idade dos filhos, visando evitar influências que levem a comportamentos agressivos. Esse ponto de vista está fundamentado na experiência desses pais, que relatam terem sido jogadores de jogos similares em sua infância e adolescência, sem terem eles próprios experienciado atitudes violentas por influência do videogame. Contudo, os pais salientam a necessidade de conversar com os filhos a fim de auxiliar a diferenciação entre realidade virtual e física. Nesse sentido, dizem ser fundamental que a criança ou o adolescente compreenda que as consequências de suas escolhas, na vida cotidiana, são diferentes das vivenciadas pelos avatares nos jogos de videogame. Assim, se cria um modo específico de se relacionar com os jogos, com a mediação dos pais sobre conteúdos violentos (Gee, 2004).

Sei que não se deve deixar jogar jogos violentos, mas assim como desde pequeno eu jogava e jogo jogos de guerra, de cometer crimes e não me influenciou em nada na minha vida, deixo ele jogar enquanto não o influenciar na vida real dele, não vejo ele como uma criança violenta por causa dos jogos e muito menos ele tentar fazer na vida real o que faz nos jogos. (Kratos, pai de Ares de 8 anos).

Meu filho joga GTA 5 como eu jogava o primeiro GTA e eu tinha 7, 8 anos também. E eu nunca saí por ai matando ninguém, nem roubando carro. O importante é deixar bem real pra criança que é só um videogame. Que é só algo virtual, que não é real. É legal usar comparações. "Olha, no jogo tal coisa acontece, mas na vida não é assim". Uma vez que ele perguntou: "Tá, mas o que acontece se eu caio do prédio?" Eu disse: "Tu morre. E aí morre mesmo." Ou quando acontece uma coisa no jogo e eu digo "Isso não é real" e ele responde "Não, né!" Ele entende. (Mário, pai de Luigi de 7 anos).

A violência na narrativa dos videogames é muitas vezes tomada como perigosa, por ter um suposto poder de contaminação que geraria comportamentos violentos nos jogadores (Gavillon, Kroeff \& Markuart, 2017), apesar disso, pesquisas não apontam aumento de comportamentos violentos em jogadores de videogame (Gee, 2009). Acreditamos que isso se deve ao fato de que, para o jogador, importa entender o jogo como um sistema de regras específico, diferente de nossa realidade, definido pela jogabilidade (Squire, 2011). Assim, o jogador entende o sangue de um inimigo, por exemplo, não em um contexto de causar mal a outra pessoa, mas como um sinal de efetividade de suas ações no jogo. Aprender a se relacionar com sistemas de regras específicos, ao invés de encorajar o mesmo comportamento em outros espaços, ajuda os jogadores a reconhecerem que em diferentes situações se aplicam diferentes regras, e não se pode transpor as ações (Squire, 2011). Os jogadores aprendem a se relacionar com regras locais, entendendo que a violência é aceitável em um ambiente fictício de jogo e não em um ambiente real. Também é importante lembrar que a morte do avatar nunca é a morte do jogador, assim, morrer em um jogo 
de tiro se assemelha mais a levar um gol no futebol do que a ser assassinado, visto que o jogador retorna para a partida. Da mesma forma, ao matarmos o avatar de outro jogador não estamos tentando eliminá-lo, esperamos que ele volte para tentar novamente e que possamos continuar a partida, "Um jogador de videogame que mata um avatar não é mais violento que um jogador de xadrez que elimina uma rainha do tabuleiro" (Gavillon, 2014).

Uma pesquisa apontou que, apesar de comportamentos agressivos serem encontrados frequentemente em partidas competitivas de League of Legends, a comunidade de jogadores é amistosa e colaborativa fora dos jogos (Golart, Kroeff \& Gavillon, 2017). Essa é uma característica dos videogames, de proporcionar a possibilidade de espaços de afinidade sobre eles de forma altamente colaborativa em que todos aprendem com todos. Podemos ver no comportamento dos pais que permitem que os filhos joguem jogos violentos, uma busca por criar espaços como estes, que a literatura aponta como sendo bastante positivos (Gee, 2009).

Apesar de os videogames não gerarem violência de forma direta, seu conteúdo pode ser pensado como o de outras mídias, como o cinema ou os livros. Seu conteúdo não é diretamente transposto para a realidade, mas eles contêm um discurso em sua narrativa, que pode ter diferentes posições. Assim, a busca dos pais por conversar com os filhos pode ajudar a interpretar estes conteúdos, apontando como estes são modos de ver o mundo específicos, e não necessariamente corretos (Squire, 2011).

\section{A constituição de redes e a dimensão coletiva dos jogos}

A dimensão coletiva está presente em muitas práticas envolvendo os videogames. Desde os primeiros arcades (máquinas de fliperama) que invadiram bares, lojas e centros de entretenimento às versões mais recentes de jogos multiplayer on-line, os videogames são produzidos para serem jogados em contextos sociais diversos.
A gente começou a fazer encontros na casa de um colega de trabalho $e$ criamos o "troféu cururu". Eu levava $o$ videogame e os quatro controles e jogávamos só futebol. Fazíamos duplas e o meu filho não sabia jogar direito ainda, mas jogava junto com a gente. E tinha colegas de trabalho que também não sabiam jogar. Então quando a gente fazia duplas, a gente colocava alguém que sabia jogar com alguém que não sabia pra ficar parelho. (Sonic, pai de Tails de 14 anos).

Além disso, jogadores também promovem espaços de convivência em torno do compartilhamento de estratégias nos modos de jogar, avaliação de consoles, notícias sobre o lançamento de novos videogames, controles e demais inovações anunciadas pelas empresas de desenvolvimento de jogos (Gee, 2004).

Vários pais relataram experiências de jogarem em lan houses ou locadoras de jogos, sozinhos ou com amigos, quando eram mais novos. Tais experiências são mais raras quando conversamos sobre os contextos sociais nos quais seus filhos costumam jogar. Com a popularização de versões domésticas dos consoles de videogames, o principal espaço para jogar deixou de ser na esfera pública em centros de entretenimento, para permanecer mais restrito ao âmbito familiar. Além do conforto de ter um videogame em casa para jogar, alguns pais consideram que tal contexto propicia experiências mais seguras para os filhos, na companhia da família.

Não tinha fliperama perto da escola, nem de casa. Mas daí eu voltava da escola a pé e fazia o caminho bem mais longo pra ir num fliper que tinha no bairro. Eu ficava olhando os guris mais velhos jogarem. Depois, eu guardava uns trocados que recebia dos pais para poder jogar. Mas daí, acho que a mãe meio que comprou o Atari pra eu não ir mais lá no fliperama, não ficar mais indo pra 
longe de casa. (Sonic, pai de Tails de 14 anos).

Outra modulação importante quanto à constituição de redes relacionadas a atividade de jogar videogame refere-se à maior popularização da internet e, consequentemente, a proliferação de espaços on-line sobre videogames. Atualmente, existem muitos blogs, sites, fóruns, canais no YouTube e outras plataformas, que são destinados a promover discussões entre jogadores mais e menos experientes entre si e entre jogadores e desenvolvedores de jogos. É possível ler dicas sobre como seguir adiante em uma fase do jogo, ou mesmo assistir o vídeo de outra pessoa jogando exatamente a parte em que se tem dificuldade de avançar. Tal recurso é utilizado também para avaliações de jogos mais novos a serem lançados no mercado e divulgação de estratégias que possibilitem ganhar bônus, descobrir conteúdos camuflados ou fazer mais pontos que os adversários ao final de uma partida.

Tinha revistas que ensinavam como virar um jogo. Às vezes tinha um jogo que estava difícil de virar e eu ia lá na banca ver as revistas. Hoje na internet tem muitos fóruns que fazem isso que as revistas faziam. Um amigo me passou um site americano que tinha como passar em todos os jogos já lançados. (Sonic, pai de Tails de 14 anos).

A comunidade on-line formada por jogadores, desenvolvedores de jogos e empresas constitui uma rede social (Sluzki, 1997) na qual os pais também buscam informações que subsidiam, por exemplo, decisões relacionadas à aquisição de novos jogos e equipamentos. Além da possibilidade de pesquisar avaliações e resenhas escritas por outros jogadores ou de inclusive observar os gráficos e recursos dos jogos nos vídeos postados, há sites que proporcionam a troca e revenda de consoles, jogos e equipamentos entre jogadores. Dessa forma, observamos a criação de um mercado informal a partir da rede social constituída nas relações on-line. Isso aumenta a possibilidade de aquisição, pois o intercâmbio de jogos e dispositivos usados apresenta menor custo. Se por um lado vemos a tendência de esvaziamento dos espaços públicos de entretenimento com videogames, por outro vemos a multiplicação de espaços online em torno da cultura dos jogos, promovendo a conexão entre milhares de jogadores.

Segundo Sluzki (1997), a rede social é composta por todo o conjunto de vínculos interpessoais de um indivíduo: famílias, amigos, relações de trabalho, de estudo, de inserção comunitária e de práticas sociais. Tal universo de relações constrói contextos sociais de convivência, domínios de ação nos quais indivíduo e meio se desenvolvem em uma dinâmica de coprodução (Kastrup, 1999), a partir de perturbações mútuas (Maturana \& Varela, 2004). Nesse sentido, sujeito e meio são compreendidos como efeitos de um processo de coprodução e transformação mútua. $\mathrm{O}$ jogador imerso na cultura dos jogos digitais não é apenas modulado como se estivesse inserido em uma realidade externa e independente de si, mas ambos são fonte recíproca de modulações um para o outro, em todo o conjunto de relações que se estabelecem no domínio de ação das práticas relacionadas a jogar videogames. Dessa forma, o jogador não está apenas agindo em um contexto, mas este está constituindo-se com ele mutuamente.

Para Maturana (2001), as emoções especificam os domínios de ações nos quais interagimos a cada instante, porque toda ação é realizada em algum domínio emocional. Ou seja, nossas emoções guiam momento a momento nosso agir, ao especificar o domínio relacional em que operamos a cada instante. No domínio de ação de jogar videogame, emoções que poderíamos nomear de positivas, relacionadas a diversão e entretenimento em família, são vivenciadas ao mesmo tempo que emergem preocupações dos pais sobre possíveis efeitos dos videogames. Essa dinâmica emocional promove a busca por práticas de aconselhamento na rede social. Assim, é comum que os pais procurem indicações a respeito de quais jogos devem 
deixar os filhos jogarem em sua rede social pessoal, ou seja, nas relações que são percebidas por cada um como significativas (Sluzki, 1997). "Como os meninos ainda são pequenos, tudo passa por nós. E todos eles foram escolhidos a dedo, através de indicações de amigos e pesquisas" (Chun-Li, mãe de Ken de 6 anos e de Ryu de 4 anos). "Tenho amigos que vivem muito esse mundo de games, então busco dicas com eles e vejo vídeos de análise de jogos na internet" (Blanka, pai de Ken de 6 anos e de Ryu de 4 anos).

Observamos que uma rede social com práticas de aconselhamento referente a cultura dos jogos digitais pode se constituir a partir do convívio cotidiano, com a presença de amigos, parentes, colegas de trabalho e vizinhos, mas também ser composta por pessoas com quem os pais costumam estabelecer relações mais esporádicas e a partir de motivações específicas, como o caso de alguns grupos online de compartilhamento de informações sobre videogames. Essa possibilidade de conectar pessoas pela internet constituiu um campo de interesse importante para a indústria dos jogos também no que se refere ao desenvolvimento dos jogos multiplayer on-line. Mais recentemente, tem se investido muito em variações desse tipo de jogo, conhecidas como MMO do gênero role-playing game (RPG), que permitem que milhares de jogadores criem personagens em um mundo virtual dinâmico e interajam entre si num contexto de jogo com regras específicas. Nesse tipo de jogo, além de controlarem seus personagens (avatares), os jogadores podem se comunicar por meio de mensagens escritas on-line e muitos oferecem também a possibilidade de comunicação entre jogadores por voz.

Entretanto, alguns pais demonstraram receios em relação a esse tipo de jogos. Tais preocupações estiveram relacionadas, principalmente, a dois aspectos: a) riscos à segurança dos filhos, e b) excesso de experiências sociais restritas ao contexto virtual. Em relação à segurança, um dos pais relatou que preferiu não comprar equipamentos de voz (microfone) e que seu filho pode jogar a versão on-line dos jogos somente quando ele está junto.

O Luigi não tem amigos virtuais no videogame. A gente joga multiplayer on-line, mas a gente não se relaciona com as pessoas. A gente só joga ali e não tem nada além disso. Acho que é muito importante jogar junto. Quando é pequeno acompanhar quando joga on-line, porque tem chat e acho que é complicado deixar sozinho, porque é arriscado. Sei lá, ele tem ingenuidade, é arriscado dele se expor. (Mário, pai de Luigi de 7 anos).

Outro pai demonstrou preocupação sobre o caminho pelo qual a indústria de jogos tem seguido, acreditando haver no mercado poucas opções de jogos multiplayer local, sem a conexão com a internet. Para ele, a possibilidade de contextos para o filho jogar com os amigos, sem a necessidade de estarem presentes em um mesmo local, vem associada à perda de outras possibilidades de ação.

Outra coisa é a preocupação com o avanço da tecnologia e o tipo de jogos que surgem. Com a evolução dos jogos on-line, acho que tu não vai mais convidar teu amigo para ir na tua casa. Tu vai estar na tua casa, o teu amigo na dele e vocês vão se encontrar no jogo cada um na sua casa. Daí se perde a questão de estar ao lado, conversarem ou depois sair pra jogar bola. (Sonic, pai de Tails de 14 anos).

Além das relações em ambientes online de jogo, a convivência social envolvendo os videogames de forma geral foi citada por quase todos os participantes da pesquisa (nove pais) como fator importante que necessita de cuidado. As principais preocupações referiramse à necessidade de limite do tempo de jogo, de forma que os filhos não deixassem de fazer outras atividades lúdicas e sociais. Uma das crenças preponderantes foi a argumentação de que, para ser uma atividade saudável, o 
videogame não pode ser uma atividade exclusiva de entretenimento. Em razão disso, em algumas famílias, o videogame pode ser utilizado somente aos finais de semana, em outras somente duas ou três vezes na semana e geralmente em um período de no máximo duas horas por vez. No restante do tempo livre, os pais costumam incentivar os filhos a fazer outras atividades recreativas, como jogar futebol, andar de bicicleta, ler livros infantojuvenis ou brincar com amigos em geral.

Principal malefício que eu vejo é com relação a pessoa ficar muito viciada, não querer largar e fazer outras tarefas, achar que aquilo ali é suficiente para tua vida ou teu final de semana. Eu sou da época que só se jogava videogame quando chovia $e$ não podia-se brincar na rua. Se tem sol, vamos pedalar, jogar bola. Ou deixa pra jogar videogame à noite, quando não vai poder sair de casa e vai estar dando novela. (Sonic, pai de Tails de 14 anos).

Alguns pais referiram, inclusive, a preocupação de que a atividade de jogar videogame não fosse vivenciada pelos filhos como uma espécie de vício. Nesse sentido, acreditavam ser importante uma atitude materna e paterna de atenção e cuidado para que os filhos possam aprender a regular seus horários e saber quando podem jogar, sem excessos e sem atrapalhar suas outras atividades.

Acho que o videogame pode ajudar a desenvolver diversas habilidades, mas ao mesmo tempo vicia e cega os meninos. Eles jogam apenas uma vez por semana, mas passam a semana inteira falando sobre o que descobriram em cada jogo. Por isso nossa preocupação em escolher com cautela os games, participar com eles e limitar o uso do aparelho. (Blanka, pai de Ken de 6 anos e de Ryu de 4 anos).

\section{A educação de mãos dadas com a diversão}

Além de atividade lúdica e recreativa, o videogame também é considerado, por muitos pais, como atividade que proporciona aprendizagens relacionadas a comportamentos ou a conteúdos. Em relação ao aspecto comportamental, acreditam que o videogame pode auxiliar no desenvolvimento de criatividade, de raciocínio lógico, de atenção distribuída, de reflexos motores e no exercício da memória, assim como a utilizar com outros tipos de dispositivos eletrônicos em geral, como celulares, iPads, computadores, etc.

Pela minha experiência pessoal e com meu filho, vejo o videogame como uma ajuda a criança a desenvolver a criatividade, raciocínio, inteligência e reflexo, visto que atiçam a criança a pensar, a serem criativos e rápidos para ganhar um jogo. (Kratos, pai de Ares de 8 anos).

Muitos jogos também proporcionam ao jogador aprender conteúdos, de forma direta ou indireta, apresentando informações que podem ser relembradas em outros contextos. Muitos pais acreditam que alguns jogos podem auxiliar na aprendizagem dos filhos na escola, pois apresentam conteúdos relacionados à geografia, à história e às ciências sociais, entre outras temáticas. Nesse sentido, um pai relatou que seu filho aprendeu a relacionar o nome de países, com o formato de sua bandeira e o lugar ao qual pertence, a partir da experiência com um videogame de futebol. De forma semelhante, outros tipos de aprendizagens ocorreriam de forma mais tangencial pela atual possibilidade gráfica dos jogos ou por se referirem a abordagem de aspectos históricos contextuais nos quais as narrativas ocorrem.

Mas eu jogava jogos de guerra e as histórias eram boas. Tipo, Killzone, a história é tri boa! (...) Eu acho que os videogames são diferentes de outros jogos, tipo jogos de cartas e tals, por causa disso. Porque eles conseguem transmitir um conteúdo para além da jogabilidade. $T u$ pode visualizar 
reproduções de lugares reais durante o jogo. (Mário, pai de Luigi de 7 anos).

Da mesma forma, alguns pais referem que eles ou os filhos aprenderam inglês pois este era o idioma padrão de vários jogos que não tinham versões em português. " $A$ pessoa acabava aprendendo por jogar videogame. (...) Eu sempre que eu posso coloco o áudio original e a legenda em inglês, justamente para não perder isso" (Sonic, pai de Tails de 14 anos).

Contudo, também observamos que a necessidade de desenvolver habilidades no manuseio dos controles e na elaboração de estratégias pode levar tempo, exigindo dos jogadores muita prática de jogo. Em relação a isso, vários pais referiram que, ao jogarem videogame com os filhos, também aproveitam a oportunidade para buscar ensinar a eles lições relacionadas à necessidade de dedicação e persistência para alcançar objetivos.

Eu acho que desafios como videogame propõe ensinam a pessoa a lidar melhor com situações difíceis até na vida real. (...) ficar horas ou dias para virar um jogo. Não tenho como comprovar, mas sinto que isto ensina a ter persistência em seus objetivos, se você quer muito alguma coisa. Estes tempos mesmo eu e ela travamos em uma fase e tentamos várias vezes $e$ morremos até chegar no estágio de fim de paciência .... Daí eu continuei jogando outras missões para o personagem ficar "mais forte" ... Ela entendeu o "espírito da coisa" e veio me ajudar... Depois de jogarmos um dia inteiro e os personagens ficarem mais "fortes" voltamos para encarar o "chefão" e matamos ele brincando. (Link, pai de Zelda de 13 anos).

Por outro lado, há situações adversas a partir desta mesma característica: a dificuldade de avançar nos jogos provocou para outros pais dinâmicas diferentes de aprendizado. Esses pais refletiram sobre sua postura como educadores, a partir de experiências nas quais os filhos pediam para que eles jogassem em seu lugar e passassem por partes do jogo nas quais não estavam obtendo sucesso, ou em situações nos jogos multiplayer, em que deixavam os filhos ganhar de propósito.

Tem jogos que ele me pede para passar de uma fase. Às vezes eu passo. Outras eu digo que não. Pra ele tentar e perder também. E aí vai ter que persistir pra ganhar. No futebol até ele ter uns 5 ou 6 anos eu deixava ele ganhar, facilitava... daí quando ele jogava contra os outros ele tinha mais dificuldade. Aí eu vi que talvez ele tenha que se esforçar pra jogar melhor desde quando estiver jogando comigo. E ele é capaz. (...) Daí eu digo pra ele que ele tem que treinar, se ele quiser se dar bem, tem que treinar. Para que ele persista até conseguir. (Mário, pai de Luigi de 7 anos).

Por fim, alguns pais também disseram que utilizam situações vivenciadas com os filhos nos videogames como exemplos em ensinamentos na educação de valores morais e éticos. Tais situações compreendem dinâmicas relacionais dos personagens dentro do jogo, como possibilidades de cooperação mútua entre os avatares para atingir objetivos comuns, mas também momentos de solidariedade entre jogadores. Nesse sentido, um dos pais citou que estava jogando com seu filho quando um dos controles do videogame parou de funcionar por ter acabado a bateria. $\mathrm{O}$ outro jogador tinha a possibilidade de tirar vantagem e continuar jogando, enquanto o outro buscava resolver o problema sozinho ou ser solidário e esperar que a situação fosse resolvida, não tirando vantagem do ocorrido. Tal situação configurouse como uma oportunidade para que pai e filho conversassem buscando estabelecer relações com outras experiências de suas vidas cotidianas. 


\section{Considerações finais}

Na literatura dos Games Studies existe a premissa de que os jogos digitais convocam para uma nova alfabetização. Desse modo, pesquisas que tragam experiências e análises de jogadores seriam diferentes daquelas análises de não jogadores. Pressupõe-se que os videogames tenham graus maiores de alfabetização nesse novo sistema semiótico e procedural inventado pelos games. Tal foi o motivo que nos fez, neste trabalho, indagar pais jogadores que apresentaram videogames a seus filhos. Não se trata, entretanto, de afirmar que análises feitas por não jogadores não sejam válidas, mas apostar na experiência de observadores inseridos.

Jogar videogame se configura como uma prática social desde a criação dos primeiros modelos de fliperamas que chegam às lojas, bares e outros estabelecimentos comerciais até a popularização dos consoles domésticos que entram em milhares de casas, envolvendo de forma mais intensa diferentes gerações na experiência com os jogos digitais. A característica imersiva e a interatividade dos videogames, aliadas aos avanços tecnológicos que diversificam os sistemas de desenvolvimento dos jogos, trazendo opções com gráficos cada vez mais realistas, contribuem para posicionamentos receosos em relação ao crescimento do espaço conquistado pelos videogames em nossa cultura. Tanto no campo científico, quanto no senso comum, existem várias controvérsias a respeito dos efeitos concretos da prática de jogar videogame.

Contudo, embora cientes de possíveis efeitos negativos dos videogames, os pais com os quais conversamos buscam basear suas decisões principalmente em experiências vivenciadas em seu cotidiano e com sua família de origem. Dessa forma, o conhecimento empírico sobre a experiência de jogar videogame parece ser considerado mais do que o conhecimento declarativo ao qual têm acesso na cultura.

Por outro lado, mesmo os pais que buscam mediar o acesso de seus filhos aos jogos, fazem uso dos videogames como um dispositivo de encontro familiar. Assim, o videogame pode aproximar os familiares, proporcionando momentos de trocas afetivas e contextos de aprendizagem importantes. Tais relações de aprendizagem não compreendem somente conteúdos escolares abordados em outros espaços no ensino formal, mas também a criação de contextos inventivos de aprendizagem entre pais e filhos relacionados a proposições éticas pertinentes a todo o convívio social. Nesse sentido, práticas envolvendo os videogames podem envolver formas de socialização em família, como o faz em outros contextos sociais.

Cabe salientar que os jogos não são neutros. Os videogames são mundos construídos, mundos que são projetados de acordo com um conjunto particular de regras que permitem certos tipos de ação. De tal modo, são espaços ideológicos. Por isso, diferentes comunidades constroem diferentes modos de participar, cooperando, competindo, o que pode eventualmente estabilizar modos de ler a tecnologia. Desta forma, uma alfabetização no domínio dos games implica também analisar os aspectos ideológicos, de valorização de determinados tipos de experiências em relação a outras possíveis.

Este foi um estudo inicial, exploratório, que não apresenta subsídios suficientes para analisar diferenças em relação a gênero ou outros marcadores específicos. Além disso, muitos estudos sobre videogames apontam a importância de considerar a experiência de jogo em sua operatividade. Neste sentido seria interessante desenvolver estudos complementares com observação participante com pais mães e filhos jogando videogame. 


\section{Referências}

Abreu, C. N., Karam, R. G., Góes, D. S., \& Spritzer, D. T. Dependência de Internet e de jogos eletrônicos: uma revisão. Revista Brasileira de Psiquiatria, 30(2), 156-167. doi:10.1590/s1516-44462008000200014

Alves, L. (2008). Relações entre os jogos digitais e aprendizagem: delineando percurso. Educação, Formação \& Tecnologias, 1(2), 3-10. Recuperado de http://eft.educom.pt/index.php/eft/article/vi ew/58

Alves, L. (2002). Jogos eletrônicos e violência: desvendando o imaginário dos screenagers. Revista FAEEBA Educação e Contemporaneidade, 11(18), 437446.

Alves, L. (2004). Jogos Eletrônicos e Violência - um Caleidoscópio de Imagens. Revista da FAEEBA - Educação e Contemporaneidade, 13(22), 365-373.

Amorim, M. C. M. S., Oliveira, E. S. G., Santos, J. A. F., \& Quadros, J. R. T. (2016). Aprendizagem e Jogos: diálogo com alunos do ensino médio-técnico. Educação \& Realidade, 41(1), 91-115. doi: 10.1590/2175-623656109

Baum, C., \& Maraschin, C. (2016). Oficinas e jogos eletrônicos: produção de saúde mental?. Interface - Comunicação, Saúde, Educação, 20(59), 1053-1062. doi: $\underline{10.1590 / 1807-57622015.0861}$

Baum, C., \& Maraschin, C. (2017). Level up! Desenvolvimento cognitivo, aprendizagem enativa e videogames. Psicologia \& Sociedade, 29, e132334. doi: $\underline{\text { 10.1590/1807-0310/2017v29132334 }}$

Baum, C., \& Maraschin, C. (2018). Subjetividade sensório-motora: Uma abordagem enativa para a emergência e transitoriedade do self. Texto inédito.

Cani, J. B., Pinheiro, I. Q., Santiago, M. E. V., \& Soares, G. M. (2017). Análise de jogos digitais em dispositivos móveis para aprendizagem de línguas estrangeiras. Revista Brasileira de Linguística Aplicada, 17(3), 455-481. doi: https://dx.doi.org/10.1590/19846398201711880
Castro Castro, C., Muñoz González, J. M., \& Brazo Millán, A. I. (2018). El uso de videojuegos serios en el aprendizaje de francés en educación superior. Revista mexicana de investigación educativa, 23(76), 157-177. Recuperado de http://www.scielo.org.mx/scielo.php?script =sci_arttext\&pid=S140566662018000100157\&lng=es\&tlng=es.

Castro, T. C., \& Gonçalves, L. S. (2018). The use of gamification to teach in the nursing field. Revista Brasileira de Enfermagem, 71(3), 1038-1045. doi: 10.1590/0034-71672017-0023

Cruz Junior, G., \& Cruz, D. M. (2016). Quando a brincadeira vira coisa séria: dos mitos e (in)verdades sobre as relações entre jogos digitais, cultura e consumo. Revista Brasileira de Ciências do Esporte, 38(2), 179-185. doi: 10.1016/j.rbce.2015.10.003

Dias, J. D., Domingues, A. N., Tibes, C. M., Zem-Mascarenhas, S. H., \& Fonseca, L. M. M. (2018). Serious games como estratégia educativa para controle da obesidade infantil: revisão sistemática da literatura. Revista Latino-Americana de Enfermagem, 26, e3036. doi: 10.1590/1518$\underline{8345.2509 .3036}$

Dumith, S., Domingues, M. R., Gigante, D. P., Hallal, P. C., Menezes, A. M. B., Kohl, H. W. (2010). Prevalence and correlates of physical activity among adolescents from Southern Brazil. Revista de Saúde Pública, 44(3), 457-467. doi:10.1590/S0034$\underline{89102010000300009}$

Faella, O., \& Luca, R.(2015). Living under attack in a one-dimensional virtual world. Revista Brasileira de Ensino de Física, 37(3), 3304-1-3304-5. doi: 10.1590/S180611173731836

Ferrari, G. L. M., Araújo, T. L., Oliveira, L. C., Matsudo, V., \& Fisberg, M. (2015). Associação entre equipamentos eletrônicos no quarto com tempo sedentário, atividade física e índice de massa corporal de crianças. Jornal de Pediatria, 91(6), 574582. doi: 10.1016/i.jped.2015.01.009 
Ferreira, R. W., Rombaldi, A. J., Ricardo, L. I. C., Hallal, P. C., \& Azevedo, M. R. (2016). Prevalência de comportamento sedentário de escolares e fatores associados. Revista Paulista de Pediatria, 34(1), 56-63. doi: 10.1016/j.rppede.2015.09.002

Frutuoso, M. F. P., Bismarck-Nasr, E. M., \& Gambardella, A. M. D. (2003). Redução do dispêndio energético e excesso de peso corporal em adolescentes. Revista de Nutrição, 16(3), 257-263. doi:10.1590/S1415-52732003000300003

Gavillon, P. (2014). Videogames e Políticas cognitivas (Dissertação de mestrado). Programa de Pós-Graduação em Psicologia Social e Institucional, Universidade Federal do Rio Grande do Sul. Porto Alegre.

Gavillon, P. Kroeff, R. Markuart, E. (2017). Relações de Competição e Violência nos Jogos Digitais. In C. Maraschin, R. Kroeff, P. Gavillon (orgs.), Oficinando com Jogos Digitais - Experiências de aprendizagem inventiva. Curitiba: Editora CRV.

Gee, J. P. (2009). Bons video games e boa aprendizagem. Perspectiva, 27(1), 167-178. doi: 10.5007/2175-795X.2009v27n1p167

Golart, J. B., Kroeff, R., \& Gavillon, P. Q. (2017). Aprendizagem Colaborativa e Violência Entre Jogadores de League of Legends. Informática na Educação: teoria \& prática, 20(1).

Gómez-Álvarez, M. C., Echeverri, J. A., \& González-Palacio, L. (2017). Estrategia de evaluación basada en juegos: Caso Ingeniería de Sistemas Universidad de Medellín. Ingeniare. Revista chilena de ingeniería, 25(4), 633-642. doi: 10.4067/S0718-33052017000400633

Gularte, D. (2010). Jogos eletrônicos: 50 anos de interação e diversão. Teresópolis: Novas Ideias.

Kastrup, V. (1999). A invenção de si e do mundo. Campinas: Papirus.

Kenski, V. (1995). O impacto da mídia e das novas tecnologias de comunicação na Educação Física. Motriz, 1(2), 129-133. Recuperado de http://www.rc.unesp.br/ib/efisica/motriz/01 n2/1_2_Vani.pdf
Leffa, V. J., Bohn, H. I., Damasceno, V. D., \& Marzari, G. Q. (2012). Quando jogar é aprender: o videogame na sala de aula. Revista de Estudos da Linguagem, 20(1). doi: 10.17851/2237-2083.20.1.209-230

Lucena, J. M. S., Cheng, L. A., Cavalcante, T. L. M., Silva, V. A., \& Farias Júnior, J. C. (2015). Prevalência de tempo excessivo de tela e fatores associados em adolescentes. Revista Paulista de Pediatria, 33(4), 407414. doi: 10.1016/j.rpped.2015.04.001

Marco, C., \& Chóliz, M. (2017). Eficacia de las técnicas de control de la impulsividad en la prevención de la adicción a videojuegos. Terapia psicológica, 35(1), 57-69. doi: 10.4067/S071848082017000100006

Martel, M. R. F., Colussi, E. L., \& Marchi, A. C. B. (2016). Efeitos da intervenção com game na atenção e na independência funcional em idosos após acidente vascular encefálico. Fisioterapia e Pesquisa, 23(1), 52-58. doi: 10.1590/18092950/14643623012016

Maturana, H. (1998). Da biologia à psicologia. Porto Alegre: Artes Médicas.

Maturana, H. R. (2001). Cognição, ciência e vida cotidiana. Belo Horizonte: Ed. UFMG.

Maturana, H., \& Varela, F. (2004). A árvore do conhecimento. Campinas: Psy.

Maturana, H. (2014). A ontologia da realidade. Belo Horizonte: Editora UFMG.

Meneghini, V., Barbosa, A. R., Mello, A. L. S. F., Bonetti, A., \& Guimarães, A. V. (2016). Percepção de adultos mais velhos quanto à participação em programa de exercício físico com exergames: estudo qualitativo. Ciência \& Saúde Coletiva, 21(4), 10331041. doi: $10.1590 / 1413-$ $\underline{81232015214.11812015}$

Natal, J. Z., Vojciechowski, A. S., Gomes, A. R. S., Rodrigues, E. V., Melo Filho, J., \& Korelo, R. I. G. (2016). Efeitos do treinamento com Kinect Sports e Kinect Adventures na resistência da musculatura lombopélvica de adultos jovens saudáveis: ensaio clínico não randomizado.

Fisioterapia e Pesquisa, 23(4), 365-371. doi: $10.1590 / 1809-2950 / 15727523042016$ 
Newman, J. (2013). Videogames. London: Routledge.

Ortiz-Colón, A.-M., Jordán, J., \& Agredal, M. (2018). Gamificación en educación: una panorámica sobre el estado de la cuestión. Educação e Pesquisa, 44, e173773. doi: 10.1590/s1678-4634201844173773

Paiva, N. M. N., \& Silva Costa, J. (2015). A influência da tecnologia na infância: desenvolvimento ou ameaça? Psicologia.pt. Recuperado de http://www.psicologia.pt/artigos/textos/A08 39.pdf

Ramos, D. K., \& Segundo, F. R. (2018). Jogos Digitais na Escola: aprimorando a atenção e a flexibilidade cognitiva. Educação \& Realidade, 43(2), 531-550. doi: 10.1590/2175-623665738

Ramos, D. K., Fronza, F. C. A. O., \& Cardoso, F. L. (2018). Jogos eletrônicos e funções executivas de universitários. Estudos de Psicologia (Campinas), 35(2), 217-228. doi: 10.1590/1982-02752018000200010

Salas-Blas, E., Merino-Soto, C., Chóliz, M., \& Marco, C. (2017). Análisis psicométrico del test de dependencia de videojuegos (TDV) en población peruana. Universitas Psychologica, 16(4), 290-302. doi:10.11144/javeriana.upsy16-4.aptd

Sluzki, C. E. (1997). A rede social na prática sistêmica: Alternativas terapêuticas. In C. Berliner (Trad.). São Paulo: Casa do Psicólogo.
Sousa, G. R. de, \& Silva, D. A. S. (2017). Sedentary behavior based on screen time: prevalence and associated sociodemographic factors in adolescents. Ciência \& Saúde Coletiva, 22(12), 40614072. doi: $10.1590 / 1413-$ 812320172212.00472016

Squire, K. D. (2011). Video games and learning: teaching and participatory culture in the digital age. New York: Teachers College Press.

Suzuki, F. T. I., Matias, M. V., Silva, M. T. A.; Oliveira, M. P. M. T. (2009) O uso de videogames, jogos de computador e internet por uma amostra de universitários da Universidade de São Paulo. Jornal Brasileiro de Psiquiatria, 58(3), 162-168. doi:10.1590/S0047-20852009000300004

Vojciechowski, A. S., Natal, J. Z., Gomes, A. R. S., Rodrigues, E. V., Villegas, I. L. P., \& Korelo, R. I. G. (2017). Effects of exergame training on the health promotion of young adults. Fisioterapia em Movimento, 30(1), 59-67. doi: 10.1590/1980-5918.030.001.ao06

Wingfield, N. (2013). Grand Theft Auto V Muscles Its Way to Sales Record. The new York Times. Recuperado em https://bits.blogs.nytimes.com/2013/09/18/gra nd-theft-auto-v-muscles-its-way-to-salesrecord/

\section{Dados sobre os autores:}

- Renata Fischer da Silveira Kroeff: Doutoranda do Programa de Pós-Graduação em Psicologia Social e Institucional (UFRGS). Especialista em Terapia Sistêmica pelo Centro de Estudos da Família e do Indivíduo (CEFI). Membro do Núcleo de Ecologias e Políticas Cognitivas (NUCOGS/UFRGS).

- Póti Quartiero Gavillon: Doutorando do Programa de Pós-Graduação em Psicologia Social e Institucional (UFRGS). Membro do Núcleo de Ecologias e Políticas Cognitivas (NUCOGS/UFRGS).

- Lígia Carangache Kijner: Mestranda em Psicologia pela Universidade do Vale do Rio dos Sinos (UNISINOS).

- Cleci Maraschin: Professora do Departamento de Psicologia Social e Institucional da Universidade Federal do Rio Grande do Sul (UFRGS). Coordenadora do Núcleo de Ecologias e Políticas Cognitivas (NUCOGS/UFRGS). 